- Reviews and investigates evidence relating malocclusion to TMD.

- Reviews and investigates evidence relating orthodontic treatment to TMD.

- Highlights the need not only for clinicians to consider whether evidence exists but also the quality of that evidence.

- Aims to place the problem of TMD in a wider context so that more informed advice can be given to patients and hence more informed treatment decisions can be made.

\title{
TMD and occlusion part I. Damned if we do? Occlusion: the interface of dentistry and orthodontics
}

\section{F. Luther ${ }^{1}$}

Objectives To review how occlusion, facial growth, TM disc position and malocclusion may relate to TMD; to review clinical studies investigating TMD pre- and post-orthodontic treatment as well as other studies linking occlusal features with TMD highlighting their limitations; and to make suggestions for improved study designs in the future in order to provide an evidence-base for clinical practice.

Design Review article.

Methods Electronic databases (MEDLINE and the Cochrane Database of Systematic Reviews) were used to select relevant and frequently cited studies (mean: 28 citations). Citation rate was confirmed using the Web of Science. Study designs are reviewed and weaknesses discussed.

Results Evidence is lacking to suggest static occlusal factors cause TMD.

Conclusions Poor study designs have led to much of the controversy over whether occlusal factors (including orthodontics) 'cause' TMD. In order to provide an evidence-base for future clinical practice, suggestions to improve study designs are made.

\section{INTRODUCTION}

TMD and dentistry

TMD (temporomandibular disorder) is a collective term embracing several clinical problems ${ }^{1}$ involving muscles, the TMJ or both. TMDs form a cluster of related disorders with common symptoms: ${ }^{1}$

- Pain - fairly localised

- Movement - limited/asymmetric

- Noises - clicks, grating etc.

This clustering of symptoms makes the condition/s awkward to diagnose and treat but as Table 1 indicates, TMD has been

\footnotetext{
Head of Academic Orthodontics, Department of Orthodontics, Child Dental Health Leeds Dental Institute, Clarendon Way, Leeds, LS2 9LU

Correspondence to: Dr Friedy Luther

Email:f.luther@leeds.ac.uk
}

\section{Online article number E2}

Refereed Paper - accepted 17 February 2006

DOI: $10.1038 /$ bdj.2006.122

${ }^{\circ}$ British Dental Journal 2007; 202: E2 found in individuals all over the world. Prevalence varies considerably however: between $7-84 \%$, with an age range within the studies of 3-74 years. Such variations may result from the differing methods of assessing TMD (for example, by questionnaire or clinical examination or both; the type and quality of questionnaire/examination used, etc) and the selection procedures adopted for the population investigated. These are dealt with elsewhere. ${ }^{2}$ Overall, it is estimated that approximately $10 \%$ of the population over the age of 18 years have pain in the TM region. ${ }^{3}$

Dentists have related TMD to occlusion for many years and this has directly impacted on patients and the treatment modalities offered. However, the quality of the studies on which this relationship has been based deserves an up-to-date review in the light of recent findings. Part I of this paper will examine the possibilities in terms of malocclusion, TM disc position, facial growth and orthodontic treatment. Part $\mathrm{II}^{4}$ will examine relationships between functional occlusion and bruxism, but will also examine important epidemiological aspects and place TMD in a wider context.

\begin{tabular}{|c|c|}
\hline Study & Country \\
\hline Solberg et al. $1979^{60}$ & USA \\
\hline Nilner and Lassing $1981^{61}$ & Sweden \\
\hline Nilner $1981^{62}$ & Sweden \\
\hline Heikinheimo et al. $1990^{63}$ & Finland \\
\hline Mohlin et al. $1991^{64}$ & Wales \\
\hline De Kanter et al. $1993^{65}$ & Netherlands \\
\hline Deng et al. $1995^{66}$ & China \\
\hline Alamoudi et al. $1998^{67}$ & Saudi Arabia \\
\hline List et al. $1999^{68}$ & Sweden \\
\hline Otuyemi et al. $2000^{69}$ & Nigeria \\
\hline Thilander et al. $2002^{70}$ & Colombia \\
\hline
\end{tabular}




\section{Literature search method}

It was not possible to carry out a systematic review as the subject matter was too wide-ranging and studies had been carried out with marked variations in their methods, making them too heterogeneous. Also, some subjects had received little or no attention in the dental literature but were nevertheless pertinent to the topic being reviewed. Therefore, study selection was based on the following premise where possible and relevant: as an unsophisticated and general rule only, important papers tend to be cited more frequently than others. ${ }^{5}$ However, many papers are never cited ${ }^{6}$ and it has been suggested ${ }^{7}$ that 35\% of existing papers are not cited in any given year whilst only about 9\% are cited twice and only 1\% six or more times. ${ }^{7}$ Furthermore, not all references are counted by citation databases, eg books. ${ }^{5}$ Thus, literature searches were carried out using MEDLINE (1966November 2005) and the Cochrane Database of Systematic Reviews but so far as was possible, studies were only included if they had been cited at least once in the literature as confirmed by the Web of Science - Science Citation Index expanded, 19001914 to 2005 (for part I: range 1-313 citations; mean 28 citations; inter-quartile range 5-30 citations). References to studies earlier than 1966 were accessed by investigation of the reference lists within the studies identified.

The TMD controversy: medicolegal and professional conduct matters. The evidence base and its relevance to dentists and orthodontists Contrasting legal cases from the UK and USA demonstrate the need for all clinicians to be aware of developments regarding TMD. In 1987 in the US ${ }^{8}$ a patient developed TMD symptoms during orthodontic treatment and the orthodontic treatment was held responsible. Evidence to suggest that orthodontics had not caused the problem was lacking. This was because it was based mostly on anecdotal case reports. ${ }^{9,10}$ The case went against the orthodontist, resulting in almost a million dollars being paid out in compensation. Subsequently, the American Association of Orthodontics funded research to investigate the relationship between orthodontics and TMD and an entire issue of the American Journal of Orthodontics and Dentofacial Orthopaedics was devoted to the subject in 1992.

In the UK, two cases have very recently come before the Professional Conduct Committee (PCC) of the GDC. In 2002 a dentist was charged with serious professional misconduct and admonished $^{11}$ as the diagnosis and advice he gave his patient (that she had early TM joint dysfunction and required further orthodontic treatment) was wholly unjustified and without any proper clinical basis. In 2005, another case was reported in the GDC Gazette. ${ }^{12}$ A dentist '...diagnosed a patient as suffering from internal derangement of the temporomandibular joint (a form of TMJ Disorder) when she did not have sufficient symptoms to justify this diagnosis and did not tell her that the treatment he proposed was not supported by informed, evidence-based opinion within the dental profession.' He did not have her informed consent and '...then persisted with this flawed (orthodontic) treatment for over six years.' The PCC found the dentist guilty of serious professional misconduct but postponed determination for 18 months. ${ }^{12}$ However, the ruling has clear implications for any dentist providing treatment. These contrasting cases demonstrate the dichotomy that exists in the literature.

Claims that orthodontic treatment may cause (or cure) TMD can be worrying for patients who may wish to discuss such matters with their dentist. However, it is generally accepted that claims in support of a particular treatment should be supported by (preferably) good evidence, which means other possibilities can be discounted. Otherwise, unsubstantiated claims may lead to problems of over or unnecessary treatment.

In Part I therefore, the aims are to review:

- How occlusion, facial growth, TM disc position and malocclusion may relate to TMD

- Clinical studies investigating TMD pre- and post-orthodontic treatment as well as other studies linking occlusal features with TMD, highlighting their limitations.

Suggestions are made to improve study designs in the future in order to provide an evidence-base for clinical practice.

\section{MALOCCLUSION AS A CAUSE OF TMD}

Various malocclusions have been associated with TMD signs or symptoms ${ }^{13-16}$ (eg class II and distal molar occlusions; anterior open bites and non-working side contacts; class III; crossbites; and deepbites). Unfortunately, these studies are difficult to perform and have generally not been carried out in an ideal manner and are therefore open to substantial criticism. A further problem when assessing the value of such clinical studies is the method by which TMD was assessed. Few studies in the orthodontic literature have used an appropriate index; the vast majority have used the Helkimo Index or a modification of it, but as highlighted by van der Weele and Dibbets ${ }^{17}$ and Luther, ${ }^{2}$ this is not appropriate. Bias is also likely to be present - workers often cannot be blinded and the authors are usually orthodontists. A detailed review of such problems has previously been undertaken. ${ }^{2,18}$

The correlations that have been reported between TMD and the various malocclusion types are low and unlikely to be of direct clinical significance (even if statistically significant). More importantly, correlation alone does not imply cause, yet the fact that such correlations exist appears to form the basis of statements such as 'Malocclusion is one of the most common causes of craniomandibular disorders. ${ }^{19}$ Furthermore, it is possible that these sorts of misapprehensions have led to orthodontic treatment being undertaken to treat TMD. However, this is not to say that any links with malocclusion are entirely spurious - it may be that more complex interpretation is required, as described below and in Part II. ${ }^{4}$ It is also necessary to investigate facial growth, as this will influence the type of malocclusion seen.

\section{MIGHT TMD CAUSE MALOCCLUSION?}

\section{Facial growth, malocclusion and TMD}

In a longitudinal cephalometric growth study, Dibbets et al. ${ }^{20}$ found that those teenagers who developed symptoms of TMD had a different facial form or appearance to those who did not. Those with symptoms tended to have longer faces and were more skeletally class II. Similar findings have been reported in more recent cephalometric studies, which also assessed disc displacement by magnetic resonance imaging (MRI) as shown in Table 2.

In contrast it has also been suggested by Schellhas and coworkers $^{21}$ that if orthodontics was undertaken for some Class II division 1 patients, the mechanics could exacerbate a preexisting internal derangement by applying forces to the joint 
possibly causing condylar necrosis. However, this suggestion has never been substantiated and the study itself was severely flawed, for example by being based on a pre-selected and thus biased sample. (For a critique of this study, see the 14 pages of letters subsequently printed in an issue of the same journal). ${ }^{22}$

The problem of distinguishing causality from correlation is returned to in Part $\mathrm{II},{ }^{4}$ but the possibility that TMD causes malocclusion rather than malocclusion causing TMD should at least be considered.

\section{TM DISC POSITION, MALOCCLUSION AND TMD}

The possibility that malocclusion could be a side-effect of TMD had not been much investigated but as MRI has become more widely available, recent studies have begun to suggest that further investigation could be justified. The best way of assessing disc position is using MRI scans.,23,24 Several studies ${ }^{25-28}$ have attempted to quantify the strength of links between malocclusion and TMD and/or disc displacement (DD) and a recurring theme is apparent: degree of skeletal class 'IIness', class III malocclusions, crossbites and asymmetry seem to be frequently related to increased prevalence of TMD and/or disc displacement.
The role of 'abnormal' disc position and the relationship with malocclusion is being actively investigated in the literature. Using methods other than MRI, several studies have reported associations between DD and some forms of untreated malocclusion, eg class III malocclusions and asymmetry, ${ }^{29,30}$ and similar associations have apparently been confirmed by others using MRI (see Table 2). For example Nebbe et al. ${ }^{31}$ reported that adolescent females with bilateral, total DD exhibited significant cephalometric differences as compared with those with normal disc position. Such studies suggest relationships may exist between facial characteristics and DD, but serious methodological problems prevent them from being clinically useful, despite their potential importance (see Table 2). Nevertheless, it is interesting that the types of malocclusion which appear to show associations with DD are similar to those which have been said to 'cause' TMD. For example, DD appears to be related to patients with class II skeletal patterns and increased vertical proportions, ie long faces as shown in Table 2. In addition, case reports exist ${ }^{32-34}$ linking condylar resorption following osteotomy with (once again) severe, long face ('high angle') class II skeletally-based malocclusions, and very recent work using biomolecular techniques has shown that these same types of

\section{Table 2 MRI Studies and malocclusion}

\begin{tabular}{|c|c|c|c|}
\hline Study & Malocclusion & Patient number & Findings \\
\hline Schellhas et al. ${ }^{21}$ & $\| / 1$ & $\begin{array}{l}128 \\
\text { Sample biased - all referred for suspected DD (letters pages }{ }^{10} \text { ) }\end{array}$ & $\begin{array}{l}112 / 128 \text { had internal derangement } \\
\text { of TMJ }\end{array}$ \\
\hline Brand et al. ${ }^{71}$ & $\begin{array}{l}\text { TMD patients } \\
\text { vs controls }\end{array}$ & $\begin{array}{l}\text { MRI + ceph study } \\
\text { TMD patients } n=24 \text {; controls } n=23 \\
\text { Ages: } 18-63 \text { years } \\
\text { TMD cases had mix of unilat \& bi DD } \\
\text { No statement re: blinding } \\
\text { No power calculation }\end{array}$ & $\begin{array}{l}\text { TMD cases had smaller mandibles and } \\
\text { maxillae }\end{array}$ \\
\hline $\begin{array}{l}\text { Fernández San } \\
\text { Román et } a l^{72}\end{array}$ & $\begin{array}{l}\text { Class I vs Class II vs } \\
\text { Class III patients }\end{array}$ & $\begin{array}{l}\text { MRI, CT + ceph study } \\
\text { Class I } n=9 ; \text { Class III } n=8 ; \text { Class II/2 } n=6 ; \text { Class III } n=25 \\
\text { Patients with facial disproportion }(n=48) \text { vs controls }(n=10 \text {, } \\
\text { confirmed no DD by MRI) } \\
\text { Ages: } 15-45 \text { years } \\
\text { No statement re: blinding }\end{array}$ & $\begin{array}{l}56 \% \text { of Class II cases had DD vs 10\% } \\
\text { Class I cases or Class III cases }\end{array}$ \\
\hline Nebbe et al. ${ }^{31}$ & $\begin{array}{l}\text { Females + Bi-DD cases } \\
\text { vs normals }\end{array}$ & $\begin{array}{l}\text { MRI + ceph study } \\
17 \text { females/grp } \\
\text { Not blinded } \\
\text { Ages: } 10-17 \text { years }\end{array}$ & $\begin{array}{l}\text { Bi-DD cases had high-angle, class II } \\
\text { characteristics }\end{array}$ \\
\hline Bósio et al. ${ }^{73}$ & $\begin{array}{l}M+F \text { symps }+B i-D D \text { vs symps } \\
\text { no DD vs asymps no DD }\end{array}$ & $\begin{array}{l}\text { MRI + ceph study } \\
\text { Matched age, sex, malocclusion. } 96 \text { people divided into } 3 \\
\text { equal-sized groups: } 32 \text { asymp with no DD; } 32 \text { symp + DD; } 32 \\
\text { asymp (7M: } 25 \text { F/grp) } \\
\text { Not blinded }\end{array}$ & $\begin{array}{l}\text { Symptomatic Bi-DDs had retrognathic } \\
\text { (ie. class II) mandible } \\
\text { NB. Started with larger sample but } \\
\text { many eliminated. }\end{array}$ \\
\hline Gidarakou et al. ${ }^{76}$ & $\begin{array}{l}\text { Asymp vols vs symp patients } \\
+ \text { Bi-DD }\end{array}$ & $\begin{array}{l}\text { MRI + ceph study } \\
46 \text { normal F vs } 42 \text { symp F } \\
\text { No statement re: blinding + no clear selection criteria } \\
\text { Selection bias }\end{array}$ & $\begin{array}{l}\text { Sig craniofacial diffs incl. SNA/SNB } \\
\text { smaller in symp grp. }\end{array}$ \\
\hline Gidarakou et al. ${ }^{75}$ & $\begin{array}{l}\text { Asymp vols vs symp patients } \\
+ \text { UDDN }\end{array}$ & $\begin{array}{l}\text { MRI + ceph study } \\
46 \text { normal F vs } 12 \text { symp F } \\
\text { Blinded but no clear selection criteria } \\
\text { Selection bias }\end{array}$ & $\begin{array}{l}\text { Craniofacial diffs found eg steeper } \\
\text { mandibular plane angle in symps. }\end{array}$ \\
\hline Gidarakou et al. ${ }^{74}$ & $\begin{array}{l}\text { Asymp vols vs symp pts } \\
+ \text { NDP }\end{array}$ & $\begin{array}{l}\text { MRI + ceph study } \\
46 \text { normal F vs } 42 \text { symp F } \\
\text { Blinded but no clear selection criteria } \\
\text { Selection bias }\end{array}$ & $\begin{array}{l}\text { No sig craniofacial diffs found except } \\
\text { greater LLS retroclination in asymps }\end{array}$ \\
\hline
\end{tabular}


patients have a different muscle make up to those with short faces. ${ }^{35}$ Thus, malocclusion - rather than causing TMD - may actually be a signal, indicative of changes occurring elsewhere about which we as yet know very little.

Indeed, whilst Paesani et al. ${ }^{36}$ in a rather unusual study were unable (using MRI) to find DD in children and babies ranging from two months old to five years old, others ${ }^{37}$ using (mostly) arthrography and (some) MRI have reported sexual dimorphism in symptomatic DD. Teenage females had three times the risk of DD compared with teenage boys, whilst the age of peak risk for DD showed no sex difference. A possible link with hormonal changes was suggested. Others have also reported DD in asymptomatic juveniles with prevalence varying with age (mean age 11 years, prevalence $8 \%{ }^{38}$ rising to $34 \%$ in a sample ranging from 6-25 years of age ${ }^{39}$ ).

However, whilst MRI studies may provide a basis for future research, study designs still require improvement and if links between DD and malocclusion are confirmed, then the relationship is unlikely to be simple. Not only is DD common in asymptomatic volunteers (34\%) but the prevalence of DD is even greater in symptomatic patients. ${ }^{39,40}$ Furthermore, of patients followed up prospectively for longer periods, ${ }^{40,41}$ only about 30\% show no improvement in their symptoms. MRI evidence of osteoarthritis and advanced stages of internal derangement are associated with a poor prognosis. Familial aggregation of joint problems also occurs. ${ }^{42}$

Whilst coincidence cannot be eliminated, the associations already described could form part of a bigger picture in which the TMJ and associated tissues are themselves affected by an underlying condition. For example, hormone (oestrogen) level reductions can be related to musculoskeletal problems. In the ovariectomised and hence osteoporotic rat (the female rat being the accepted animal model for human, postmenopausal osteoporosis), bone shape, quantity and quality is detrimentally affected by hormonally provoked atrophy and osteoporosis. ${ }^{43}$ On the other hand, healthy rats given plenty of exercise show improvements in muscle/tendon structure and thickness, bone quantity, quality and form. ${ }^{44}$ These muscle and tendon insertions comprise collagen type III (Sharpey) fibres - the same type of collagen which is affected in the genetic disorder Ehlers-Danlos syndrome. Genetic factors can influence tissue response and are known to influence human susceptibility to osteoporosis. ${ }^{45}$ Furthermore, a genetic disorder known as generalised joint hypermobility (GJH) may be related to some forms of TMD and GJH is itself associated with some forms of Ehlers-Danlos syndrome. Unfortunately, we still await definitive evidence of whether such links definitely exist in connection with human TMD: a recent systematic review ${ }^{46}$ concluded $^{-}$ that it is not clear whether GJH is associated with TMD because of the methodological flaws present in the various studies reviewed.

Having said all of this, a recent study ${ }^{47}$ assessed 3,033 subjects to investigate the relationship between self-reported TMD symptoms, overjet and overbite but found no association. There could be various explanations for this (including that there is no association), but the findings of all of these studies provide more questions than answers and at this stage highlight the need for studies to have sound methods - avoiding bias and the other problems so prevalent in much of the previous literature.
In summary at this stage, the possibility that TMD affects facial growth (hence malocclusion) cannot yet be dismissed. There is, however, another way of looking at the problem: to investigate the effects of orthodontic treatment on TMD. If malocclusion caused TMD, presumably TMD sufferers would be cured by orthodontics or the prevalence of TMD would at least be much reduced. These types of studies will be reviewed next.

\section{ORTHODONTICS AND TMD}

\section{Does orthodontics cause TMD?}

Clinical studies examining orthodontic treatment have investigated possible links between orthodontics and TMD by comparing symptoms and/or signs of TMD in:

- Treated versus untreated patients

- Patients treated by different means

- Longitudinal studies - the same patients are compared before and after treatment.

Other methods have also been adopted, eg comparing joint spaces cephalometrically before and after treatment, but the assumptions and methods on which such studies are based are in any case flawed ${ }^{2}$ and will not be discussed here. Many of the weaknesses associated with orthodontic studies have been reviewed previously ${ }^{2,18}$ and the problems of how TMD is assessed should be remembered, as few studies in the orthodontic literature have used an appropriate index; the vast majority have tended to use the Helkimo Index or a modification of this but this - as has been highlighted previously ${ }^{2,17}$ - is not appropriate.

\section{Studies comparing treated versus untreated patients}

Many such studies have been undertaken (see Table 3) and most have used patients with a mixture of malocclusions. Only those asterisked in Table 3 have undertaken studies of patients with specific types of malocclusion. ${ }^{50-53}$ This is relevant, as it has been argued that failure to segregate samples sufficiently causes dilution of the very effects one is looking for. ${ }^{54}$

Henrikson and Nilner ${ }^{53}$ compared 11-15 year old, treated and untreated female subjects with class II division 1 malocclusions - defined as having uni- or bilateral class II relations of at least half a cusp ( $n=65$ and $n=58$ respectively). These subjects were compared with females with normal occlusions (n $=60$ ). Patients were recruited prospectively and consecutively from a treatment waiting list; they were treated with fixed appliances (some with headgear, class II elastics and 50\% with extractions). All other individuals, ie untreated subjects, were recruited from school screening programmes; drop outs were also accounted for. Assessments for these prospective studies were undertaken 'blind' to an extent; Henrikson also adopted some principles advocated in one of the more valid and reproducible TMD assessment indices - the Research Diagnostic Criteria (RDC)..$^{55}$

As a result of such improvements in study design, Henrikson's work may provide more insight into the true association (or otherwise) between orthodontics and TMD. He found that subjects with normal occlusions had the lowest prevalence of TMD signs compared with those with treated or untreated class II division 1 malocclusions, who always had a higher prevalence of TMD signs/symptoms. Treated class II division 1 
patients had a lower prevalence of TMD signs/symptoms than untreated subjects with a similar malocclusion. Henrikson and Nilner ${ }^{56}$ suggested that this may be due to improvements in dental occlusion and occlusal stability, but these studies were not designed to confirm this nor do they exclude other explanatory factors.

\section{Studies comparing patients treated by different means}

These studies compare and contrast treatment mechanics that maximise differences in condyle position, testing the assumption that treatment mechanics trap the mandible posteriorly, forcing the TM disc anteriorly which has been said to 'cause' TMD. ${ }^{2,9}$ Such specific, longitudinal studies have been undertaken infrequently for obvious reasons: large sample sizes are likely to be necessary to achieve sufficient statistical power (to ensure that sufficient numbers of patients are included to find a clinically significant difference should one exist) and patient drop out may be high over the long periods required. However, Dibbets and van der Weele ${ }^{57}$ compared children who had either been treated with four premolar extractions and Begg fixed appliances $(n=72)$ or non-extraction with activator functional appliances $(n=63)$. Patients were assessed before treatment, four years post-retention and finally at 10 years after the start of orthodontic treatment. Signs and symptoms of TMD increased with age but 10 years after the study had started, the initial differences in symptoms and signs between the two groups no longer existed. This suggested that age was a confounding factor: the prevalence of TMD increases with age - children treated with functional appliances start their treatment earlier and thus have a lower prevalence of TMD initially.

\section{Longitudinal studies}

A number of such studies have been undertaken (see Table 4) and again require especially good, long-term follow up. Recently, a meta-analysis ${ }^{58}$ concluded that the data did not indicate that traditional orthodontic treatment increased the prevalence of TMD.

\section{Orthodontics and functional occlusal factors}

It has been suggested that an internal derangement may be caused by the mandible being retracted during some forms of orthodontic treatment. ${ }^{59}$ Premolar extractions in the upper arch (as might be needed for overjet reduction) have been said to cause the mandible to be trapped, forcing the TM disc anteriorly due to the condyle having been forced posteriorly. ${ }^{9}$ However, as reported previously ${ }^{2}$ there is no evidence to support this idea and for example, the work of Wyatt ${ }^{59}$ was based only on personal opinion.

A further possibility - often implied rather than explicitly stated in the literature ${ }^{60}$ - is that some occlusal contacts (such as non-working side contacts or interferences) may trigger clenching or grinding which causes TMD. Such contacts may occur normally or could be introduced during orthodontic treatment. Studies investigating these possibilities will be discussed in Part II. ${ }^{4}$ Displacements on closure (for example as associated with crossbites) have also been implicated and have been the subject of a Cochrane Systematic Review. ${ }^{61}$ However, whilst the primary outcome measures assessed included patient orientated outcomes such as resolution of pain and clicking as a result of treatment, the studies that could finally be included rarely actually reported such outcomes. In fact only two trials reported any patient orientated outcomes and these related to treatment times.

\section{Orthodontics as a 'cure' for TMD}

Various possibilities have been suggested, but a popular approach adopted by several authors has been to use orthodontics to help 'recapture' the TM disc and thus help treat TMD. However, these suggestions are based on case reports, case series or anecdotal evidence and, as Okeson ${ }^{1}$ has stated, management of TMD has been primarily based on treatments selected by the clinician's personal biases. These aspects will therefore not be reviewed further here.

Table 3 Studies comparing treated versus untreated patients

\begin{tabular}{|c|c|}
\hline Study & Country \\
\hline Sadowsky and Begole $1980^{77}$ & USA \\
\hline Sadowsky and Polson $1984^{78}$ & USA \\
\hline Larsson and Rönnerman $1981^{79}$ & Sweden \\
\hline${ }^{*} J a n s o n$ and Hasund $1981^{48}$ & Norway \\
\hline Dahl et al. $1988^{80}$ & Norway \\
\hline${ }^{*} \mathrm{Ke} ß$ et al. $1991^{49}$ & Germany \\
\hline Egermark and Thilander $1992^{81}$ & Sweden \\
\hline Hirata et al. $1992^{82}$ & USA \\
\hline Wadhwa et al. $1993^{83}$ & India \\
\hline Lagerstrom et al. $1998^{84}$ & Sweden \\
\hline${ }^{*}$ Henrikson $1999^{50}$ & Sweden \\
\hline${ }^{*}$ Henrikson and Nilner $2003^{51}$ & Sweden \\
\hline
\end{tabular}

\begin{tabular}{|c|c|}
\hline Study & Country \\
\hline Pancherz $1985^{85}$ & Sweden \\
\hline Sadowsky et al. $1991^{86}$ & USA \\
\hline Dibbets and van der Weele $1992^{87}$ & Netherlands \\
\hline${ }^{*}$ Rendell et al. $1992^{88}$ & USA \\
\hline Kremenak et al. 1992 parts I and II89,90 & USA \\
\hline Egermark and Thilander $1992^{81}$ & Sweden \\
\hline Hirata et al. $1992^{82}$ & USA \\
\hline O'Reilly et al. $1993^{91}$ & USA \\
\hline Egermark and Rönnerman $1995^{92}$ & Sweden \\
\hline Olsson and Lindqvist $1995^{93}$ & Sweden \\
\hline Keeling et al. $1995^{94}$ & USA \\
\hline Ngan et al. $1997^{95}$ & Hong Kong \\
\hline Henrikson et al. $1999^{96}$ & Sweden \\
\hline Henrikson and Nilner $2000^{54}$ & Sweden \\
\hline Henrikson et al. $2000^{97}$ & Sweden \\
\hline Imai et al. $2000^{98}$ & Japan \\
\hline Egermark et al. $2003^{28}$ & Sweden \\
\hline
\end{tabular}


The overall findings of orthodontic clinical studies

Currently, and based on the available evidence, the widely accepted conclusion is that orthodontic treatment neither causes nor cures TMD. ${ }^{2,58}$ If further studies are planned, they should (so far as is possible):

- Be prospective

- Be undertaken by clinicians using a reproducible and validated index

- Be undertaken by clinicians blind to which group the patients belong to

- Have patients randomly allocated to treatment/ control groups

- Be appropriately powered

- Include patients of similar backgrounds with similar malocclusions and who are compared with appropriate controls.

However, whilst many people undergo orthodontic treatment, even more people do not and since TMD appears to be a common condition, such 'orthodontics only' studies will do little to investigate the major causes of TMD or the best treatments. It would therefore be useful to review other features and factors which may have a more significant role to play in the aetiology of TMD. Such aspects are reviewed in Part II. ${ }^{4}$

1. Okeson J P. Differential diagnosis and management considerations of temporomandibular disorders. In Okeson J P (ed) Orofacial pain: guidelines for assessment, diagnosis and management. pp 113-184. Chicago: Quintessence Publishing Co, Inc, 1996.

2 Luther F. Orthodontics and the temporomandibular joint. Where are we now? Part 1: orthodontic treatment and temporomandibular disorders. Angle Orthod 1998: 68: 295-304

3. LeResche L. Epidemiology of temporomandibular disorders: implications for the investigation of etiologic factors. Crit Rev Oral Biol Med 1997; 8: 291-305.

4. Luther F. TMD and occlusion part II. Damned if we don't? Functional occlusal problems: TMD epidemiology in a wider context. Br Dent $J$ in press.

5. Adam D. Citation analysis: the counting house. Nature 2002; 415: 726-729.

6. Seglen P O. Why the impact factor of journals should not be used for evaluating research. BrMed J 1997; 314: 497.

7. de Solla Price D J. Networks of scientific papers. The pattern of bibliographic references indicates the nature of the scientific research front. Science 1965 149: $510-515$.

8. Pollack B. Cases of note. Michigan jury awards $\$ 850,000$ on ortho case: a tempest in a teapot. Am J Orthod Dentofacial Orthop 1988; 94: 358-360.

9. Giannelly A A. Orthodontics, condylar position and temporomandibular joint status. Am J Orthod Dentofacial Orthop 1989; 95: 521-523.

10. Reynders R M. Orthodontics and temporomandibular disorders: a review of the literature (1966-1988). Am J Orthod Dentofacial Orthop 1990; 97: 463-471.

11. Conduct cases reviewed. GDC Gazette, Summer 2002: 10-11.

12. Conduct cases reviewed. GDC Gazette, Summer 2005: 22, 25 .

13. Mohlin B, Ingervall $B$, Thilander B. Relation between malocclusion and mandibular dysfunction in Swedish men. Eur J Orthod 1980; 2: 229-238.

14. Mohlin B, Thilander B. The importance of the relationship between malocclusion and mandibular dysfunction and some clinical applications in adults. Eur $J$ Orthod 1984; 6: 192-204.

15. Egermark-Eriksson I, Ingervall B, Carlsson G E. The dependence of mandibular dysfunction in children on functional and morphologic malocclusion. Am J Orthod 1983; 83: 187-194.

16. Brandt D. Temporomandibular disorders and their association with morphologic malocclusion in children. In Carlson D S, McNamara J A, Ribbens K A (eds) Developmental aspects of temporomandibular disorders. pp 279-298. Ann Arbor: University of Michigan, 1985 (Craniofacial Growth Series 16).

17. van der Weele L T, Dibbets J M H. Helkimo index: a scale or just a set of symptoms? J Oral Rehabil 1987; 14: 229-237.

18. Luther F. Orthodontics and the temporomandibular joint. Where are we now? Part 2: functional occlusion, malocclusion and TMD. Angle Orthod 1998; 68: $305-318$

19. Higson R. The controversy over occlusion. The Dentist 1992; pp 28, 39.

20. Dibbets J M H, van der Weele L T, Uildriks A K. Symptoms of TMJ dysfunction: indicators of growth patterns? J Pedod 1985; 9: 265-284.

21. Schellhas K P, Pollei S R, Wilkes C H. Pediatric internal derangements of the temporomandibular joint: effect on facial development. Am J Orthod Dentofacial Orthop 1993: 104: 51-59.

22. Letters to the Editor. Am J Orthod Dentofacial Orthop 1994; 105: 25A-39A.

23. Liedberg J, Panmekiate S, Petersson A, Rohlin M. Evidence-based evaluation of three imaging methods for the temporomandibular disc. Dentomaxillofac Radiol 1996: 25: 234-241.

24. Brooks S L, Brand J W, Gibbs S J et al. Imaging of the temporomandibular joint: a position paper of the American Academy of Oral and Maxillofacial Radiology. Oral Surg Oral Med Oral Pathol Oral Radiol Endod 1997; 83: 609-618.

25. Pullinger A G, Seligman D A, Gornbein J A. A multiple logistic regression analysis of the risk and relative odds of temporomandibular disorders as a function of common occlusal features. J Dent Res 1993; 72: 968-979.

26. Kahn J, Tallents R H, Katzberg R W, Ross M E, Murphy W C. Prevalence of dental occlusal variables and intraarticular temporomandibular disorders: molar relationship, lateral guidance, and non-working side contacts. J Prosthet Dent 1999; 82: $410-415$

27. Pullinger A G, Seligman D A. Quantification and validation of predictive values of occlusal variables in temporomandibular disorders using a multifactorial analysis. J Prosthet Dent 2000; 83: 66-75.

28. Egermark I, Magnusson T, Carlsson G E. A 20-year follow-up of signs and symptoms of temporomandibular disorders and malocclusions in subjects with and without orthodontic treatment in childhood. Angle Orthod 2003; 73: 109-115.

29. Kobayashi T, Honma K, Izumi K et al. Temporomandibular joint symptoms and disc displacement in patients with mandibular prognathism. Br J Oral Maxillofac Surg 1999; 37: 455-458.

30. Muto T, Kawakami J, Kanazawa M et al. Relationship between disc displacement and morphologic features of skeletal class III malocclusion. Int J Adult Orthodon Orthognath Surg 1998; 13: 145-151.

31. Nebbe B, Major P W, Prasad N G. Adolescent female craniofacial morphology associated with advanced bilateral TMJ disc displacement. Eur J Orthod 1998; 20: 701-712

32. Hoppenreijs T J M, Freihofer H P, Stoelinga P J, Tuinzing D B, van't Hof M A. Condylar remodelling and resorption after Le Fort I and bimaxillary osteotomies in patients with anterior open bite. A clinical and radiological study. Int J Oral Maxillofac Surg 1998; 27: 81-91.

33. Hoppenreijs T J M, Stoelinga P J, Grace K L, Robben C M. Long-term evaluation of patients with progressive condylar resorption following orthognathic surgery. Int J Oral Maxillofac Surg 1999; 28: 411-418.

34. Hwang S J, Haers P E, Zimmermann A et al. Surgical risk factors for condylar resorption after orthognathic surgery. Oral Surg Oral Med Oral Pathol Oral Radiol Endod 2000; 89: 542-552.

35. Nelson-Moon Z L, Morgan M J, Gilthorpe M S. Help or hindrance? The relevance of masseteric adaptability to vertical facial development. Eur J Orthod 2003; 25: 435, Abstract 41.

36. Paesani D, Salas E, Martinez A, Isberg A. Prevalence of temporomandibular joint disk displacement in infants and young children. Oral Surg Oral Med Oral Pathol Oral Radiol Endod 1999; 87: 15-19.

37. Isberg A, Hägglund M, Paesani D. The effect of age and gender on the onset of symptomatic temporomandibular joint disk displacement. Oral Surg Oral Med Oral Pathol Oral Radiol Endod 1998; 85: 252-257.

38. Hans M G, Liberman J, Goldberg J, Rosencweig G, Bellon E. A comparison of clinical examination history and magnetic resonance imaging for identifying orthodontic patients with temporomandibular joint disorders. Am J Orthod Dentofacial Orthop 1992; 101: 54-59.

39. Ribeiro R F, Tallents R H, Katzberg R W et al. The prevalence of disc displacement in symptomatic and asymptomatic volunteers aged $6-25$ years. J Orofac Pain 1997; 11: 37-47.

40. Kurita K, Westesson P L, Yuasa H et al. Natural course of untreated symptomatic temporomandibular joint disc displacement without reduction. J Dent Res 1998; 77: $361-365$

41. Sato $S$, Goto S, Kawamura H, Motegi K. The natural course of nonreducing disc displacement of the TMJ: relationship of clinical findings at initial visit to outcome after 12 months without treatment. J Orofac Pain 1997: 11: 315-320.

42. Morrow D, Tallents R H, Katzberg R W, Murphy W C, Hart T C. Relationship of other joint problems and anterior disc displacement in symptomatic TMD patients and in asymptomatic volunteers. J Orofac Pain 1996; 10: 15-20.

43. Luther F, Saino H, Carter D H, Aaron J E. Evidence for an extensive collagen type III/VI proximal domain in the rat femoral cortex: I. Diminution with ovariectomy. Bone 2003; 32: 652-659.

44. Saino $H_{\text {, Luther }} \mathrm{F}_{\text {, Carter }} \mathrm{D} \mathrm{H}$ et al. Evidence for an extensive collagen type III proximal domain in the rat femoral cortex: II. Expansion with exercise. Bone 2003; 32: 660-668.

45. Lindsay R, Cosman F. Primary osteoporosis. In Coe F L, Favus M J (eds) Disorders of bone and mineral metabolism. pp 831-888. New York: Raven Press, 1992.

46. Dijkstra P U, Kropmans T J B, Stegenga B. The association between generalised joint hypermobility and temporomandibular joint disorders: a systematic review. J Dent Res 2002; 81: 158-163.

47. John M T, Hirsch C, Drangsholt M T, Mancl L A, Setz J M. Overbite and overjet are not related to self-report of temporomandibular disorder symptoms. J Dent Res 2002; 81: 164-169.

48. Janson $M$, Hasund $A$. Functional problems in orthodontic patients out of retention. Eur J Orthod 1981; 3: 173-179.

49. Keß K, Bakopulos K, Witt E. TMJ function with and without orthodontic treatment. Eur J Orthod 1991; 13: 192-196.

50. Henrikson T. Temporomandibular disorders and mandibular function in relation to class II malocclusion and orthodontic treatment. A controlled, prospective and longitudinal study. Swed Dent J (Suppl) 1999; 134: 5-62.

51. Henrikson T, Nilner M. Temporomandibular disorders, occlusion and orthodontic treatment. J Orthod 2003; 30: 129-137, discussion 127. 
52. Storey A T. Functional stability of orthdontic treatment - occlusion as a cause of temporomandibular disorders. In Nanda R, Burstone C J (eds) Retention and stability in orthdontics. pp 203-215. Philadelphia: WB Saunders, 1993.

53. Dworkin S F, LeResche L. Research diagnostic criteria for temporomandibular disorders: review, criteria, examinations and specifications, critique. J Craniomandib Disord 1992; 6: 301-355.

54. Henrikson T, Nilner M. Temporomandibular disorders and the need for stomatognathic treatment in orthodontically treated and untreated girls. Eur J Orthod 2000: 22: 283-292.

55. Dibbets J M, van der Weele L T. Orthodontic treatment in relation to symptoms attributed to dysfunction of the temporomandibular joint. A 10-year report of the University of Groningen study. Am J Orthod Dentofacial Orthop 1987; 91: 193-199.

56. Kim M R, Graber T M, Viana M A. Orthodontics and temporomandibular disorder: a meta-analysis. Am J Orthod Dentofacial Orthop 2002; 121: 438-446.

57. Wyatt W E. Preventing adverse effects on the temporomandibular joint through orthodontic treatment. Am J Orthod Dentofacial Orthop 1987; 91: 493-499.

58. Gray R J M, Davies S J, Quayle A A. Examination of the articulatory system. In A clinical guide to temporomandibular disorders. pp 19-25. London: British Dental Association, 2002

59. Harrison J E, Ashby D. Orthodontic treatment for posterior crossbites (Cochrane Review). In The Cochrane Library. Issue 2. Chichester: John Wiley \& Sons, Ltd, 2004.

60. Solberg W K, Woo M W, Houston J B. Prevalence of mandibular dysfunction in young adults. J Am Dent Assoc 1979; 98: 25-34.

61. Nilner M, Lassing S. Prevalence of functional disturbances and diseases of the stomatognathic system in 7-14 year olds. Swed Dent J 1981; 5: 173-187.

62. Nilner M. Prevalence of functional disturbances and diseases of the stomatognathic system in 15-18 year olds. Swed Dent J 1981; 5: 189-197.

63. Heikinheimo K, Salmi K, Myllärniemi S, Kirveskari P. A longitudinal study of occlusal disorders at the ages of 12 and 15 years. Eur J Orthod 1990; 12: 190-197.

64. Mohlin B, Pilley J, Shaw W. A survey of craniomandibular disorders in 1000 12 -year-olds. Study design and baseline data in a follow-up study. Eur J Orthod 1991; 13: 111-123.

65. De Kanter R J, Truin G J, Burgersdijk R C et al. Prevalence in the Dutch adult population and a meta-analysis of signs and symptoms of temporomandibular disorder. J Dent Res 1993; 72: 1509-1518.

66. Deng Y, Min Kui F, Hägg U. Prevalence of temporomandibular joint dysfunction (TMJD) in Chinese children and adolescents. A cross-sectional epidemiological study. Eur J Orthod 1995; 17: 305-309.

67. Alamoudi N, Farsi N, Salako N, Feteih R. Temporomandibular disorders among school children. J Clin Pediatr Dent 1998; 22: 323-329.

68. List T, Wahlund K, Wenneberg B, Dworkin S F. TMD in children and adolescents: prevalence of pain, gender differences, and perceived treatment need. J Orofac Pain 1999; 13: 9-20.

69. Otuyemi O D, Owotade F J, Ugboko V I, Ndukwe K C, Olusile O A. Prevalence of signs and symptoms of temporomandibular disorders in young Nigerian adults. J Orthod 2000; 27: 61-65.

70. Thilander B, Rubio G, Pena L, de Mayorga C. Prevalence of temporomandibular dysfunction and its association with malocclusion in children and adolescents: an epidemiologic study related to specified stages of dental development. Angle Orthod 2002; 72: 146-154.

71. Brand J W, Nielson K J, Tallents R H et al. Lateral cephalometric analysis of skeletal patterns in patients with and without internal derangement of the temporomandibular joint. Am J Orthod Dentofacial Orthop 1995; 107: 121-128.

72. Fernández San Román J, Gomez Gonzalez J M, del Hoyo J A. Relationship between condylar position, dentofacial deformity and temporomandibular joint dysfunction: an MRI and CT prospective study. J Craniomaxillofac Surg 1998; 26: $35-42$.

73. Bósio J A, Burch J G, Tallents R H, Wade D B, Beck F M. Lateral cephalometric analysis of asymptomatic volunteers and symptomatic patients with and without bilateral temporomandibular joint disk displacement. Am J Orthod Dentofacial Orthop 1998; 114: 248-255.

74. Gidarakou I K, Tallents R H, Kyrkanides S, Stein S, Moss M E. Comparison of skeletal and dental morphology in asymptomatic volunteers and symptomatic patients with normal temporomandibular joint. Angle Orthod 2003; 73: 116-120.

75. Gidarakou I K, Tallents R H. Kyrkanides S. Stein S. Moss M E. Comparison of skeletal and dental morphology in asymptomatic volunteers and symptomatic patients with unilateral disk displacement without reduction. Angle Orthod 2003; 73: 121-127.
76. Gidarakou I K, Tallents R H, Kyrkanides S, Stein S, Moss M E. Comparison of skeletal and dental morphology in asymptomatic volunteers and symptomatic patients with bilateral disk displacement with reduction. Angle Orthod 2002; 72: 541-546.

77. Sadowsky $C, B e G o l e ~ E A$. Long-term status of temporomandibular joint function and functional occlusion after orthodontic treatment. Am J Orthod 1980; 78: 201-212.

78. Sadowsky C, Polson A M. Temporomandibular disorders and functional occlusion after orthodontic treatment: results of two long-term studies. Am J Orthod 1984; 86: 386-390.

79. Larsson E, Ronnerman A. Mandibular dysfunction symptoms in orthodontically treated patients ten years after the completion of treatment. Eur J Orthod 1981; 3: 89-94.

80. Dahl B J, Krogstad B S, Øgaard B, Eckersberg T. Signs and symptoms of craniomandibular disorders in two groups of 19-year-old individuals, one treated orthodontically and the other not. Acta Odontol Scand 1988; 46: 89-93.

81. Egermark I, Thilander B. Craniomandibular disorders with special reference to orthodontic treatment: an evaluation from childhood to adulthood. Am J Orthod Dentofacial Orthop 1992; 101: 28-34

82. Hirata R H, Heft M W, Hernandez B, King G J. Longitudinal study of signs of temporomandibular disorders (TMD) in orthodontically treated and nontreated groups. Am J Orthod Dentofacial Orthop 1992; 101: 35-40.

83. Wadhwa L, Utreja A, Tewari A. A study of clinical signs and symptoms of temporomandibular dysfunction in subjects with normal occlusion, untreated, and treated malocclusion. Am J Orthod Dentofacial Orthop 1993; 103: 54-61.

84. Lagerstrom L, Egermark I, Carlsson G E. Signs and symptoms of temporomandibular disorders in 19-year-old individuals who have undergone orthodontic treatment. Swed Dent J 1998; 22: 177-186.

85. Pancherz $\mathrm{H}$. The Herbst appliance: its biological effect and clinical use. Am J Orthod 1985; 87: 1-20.

86. Sadowsky C, Theisen T A. Sakols EI. Orthodontic treatment and temporomandibular joint sounds: a longitudinal study. Am J Orthod Dentofacial Orthop 1991; 99: 441-447.

87. Dibbets J M H, van der Weele L T. Long-term effects of orthodontic treatment, including extractions, on signs and symptoms attributed to CMD. Eur J Orthod 1992; 14: 16-20.

88. Rendell J K, Norton L A, Gay T. Orthodontic treatment and temporomandibular joint disorders. Am J Orthod Dentofacial Orthop 1992; 101: 84-87.

89. Kremenak C R, Kinser D D, Harman H A, Menard C C, Jakobsen J R. Orthodontic risk factors for temporomandibular disorders (TMD) I: premolar extractions. Am J Orthod Dentofacial Orthop 1992; 101: 13-20.

90. Kremenak C R, Kinser D D, Melcher T J et al. Orthodontics as a risk factor for temporomandibular disorders (TMD) II. Am J Orthod Dentofacial Orthop 1992: 101: 21-27.

91. O'Reilly M T, Rinchuse D J, Close J. Class II elastics and extractions and temporomandibular disorders: a longitudinal prospective study. Am J Orthod Dentofacial Orthop 1993; 103: 459-463.

92. Egermark I, Ronnerman A. Temporomandibular disorders in the active phase of orthodontic treatment. J Oral Rehabil 1995; 22: 613-618.

93. Olsson $M$, Lindqvist B. Mandibular function before and after orthodontic treatment. Eur J Orthod 1995; 17: 205-214.

94. Keeling S D, Garvan C W, King G J, Wheeler T T, McGorray S. Temporomandibular disorders after early Class II treatment with bionators and headgears: results from a randomized controlled trial. Semin Orthod 1995; 1: 149-164.

95. Ngan P W, Yiu C, Hägg U, Bowley J. Masticatory muscle pain before, during and after treatment with orthopedic protraction headgear: a pilot study. Angle Orthod 1997; 67: 433-437.

96. Henrikson T, Nilner M, Kurol J. Symptoms and signs of temporomandibular disorders before, during and after orthodontic treatment. Swed Dent J 1999; 23: 193-207.

97. Henrikson T, Nilner M, Kurol J. Signs of temporomandibular disorders in girls receiving orthodontic treatment: a prospective and longitudinal comparison with untreated Class II malocclusions and normal occlusion subjects. Eur J Orthod 2000; 22: 271-281.

98. Imai T, Okamoto T, Kaneko T et al. Long-term follow-up of clinical symptoms in TMD patients who underwent occlusal reconstruction by orthodontic treatment. Eur J Orthod 2000; 22: 61-67. 